TecnoLógicas

ISSN-p 0123-7799

ISSN-e 2256-5337

Vol. 22, No. 44

Enero-abril de 2019

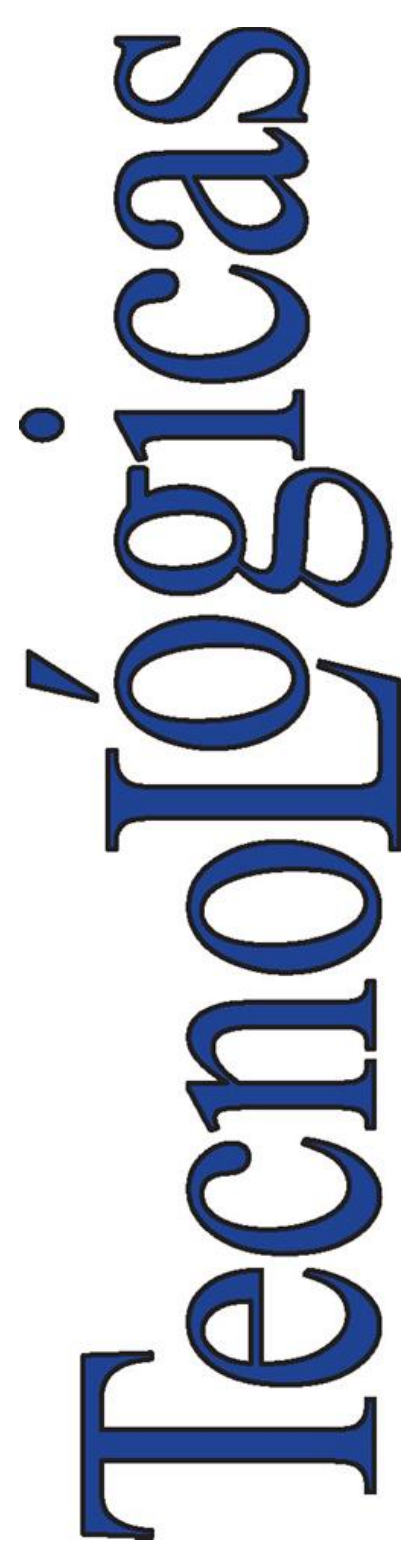

(C) Instituto Tecnológico Metropolitano Este trabajo está licenciado bajo una Licencia Internacional Creative Commons Atribución (CC BY-NC-SA)

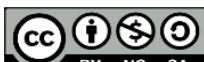

Artículo de Investigación/Research Article

\section{Location and optimal sizing of photovoltaic sources in an isolated mini-grid}

\section{Ubicación y dimensionamiento óptimo de fuentes fotovoltaicas en una mini-red aislada}

\author{
Juliana Jiménez ${ }^{1}$, John E. Cardona², y Sandra X. Carvajal ${ }^{3}$
}

Recibido: 13 de junio de 2018

Aceptado: 22 de octubre de 2018

\begin{abstract}
Cómo citar / How to cite
J. Jiménez, J. E. Cardona, S.X. Carvajal, Location and optimal sizing of photovoltaic sources in an isolated mini-grid. TecnoLógicas, vol. 22, no. 44, pp. 61-80, 2019. https://doi.org/10.22430/22565337.1182
\end{abstract}

1 Electrical Engineer, Department of Electrical Engineering, Electronics and Computing, Universidad Nacional de Colombia, Manizales-Colombia, jjimenezmu@unal.edu.co

2 MSc. Electrical Engineering, Electrical Engineer, Transmission and Distribution Area, Empresa de Energía del Pacífico S.A. E.S.P., PalmiraColombia, jecardona@celsia.com

$3 \mathrm{PhD}$ in Engineering, MSc. Electrical Engineering, Electrical Engineer, Department of Electrical Engineering, Electronics and Computer Science, Universidad Nacional de Colombia, Manizales-Colombia, sxcavajalq@unal.edu.co 


\begin{abstract}
This article introduces a new mixed integer linear programming model that guarantees the optimal solution to the location and sizing problem of distributed photovoltaic generators in an isolated mini-grid. The solar radiation curves of each node in the minigrids were considered, and the main objective was to minimize electric power losses in the operation of the system. The model is non-linear in nature because some restrictions are not linear. However, this article proposes the use of linearization techniques to obtain a linear model with a global optimal solution, which can be achieved through commercial solvers; CPLEX in this case. The proposed model was tested in an isolated 14-bus mini-grid, based on real data of topology, demand and generation adapted to a balanced operation. This model shows, as a result, the optimal location of photovoltaic generators and their optimal capacity produced by the maximum active power delivered at the maximum solar irradiation time of the region. It is also evident that the hybrid operation between small hydroelectric power plants and photovoltaic generation improves the network voltage profile and the electric power losses without the use power storage systems.
\end{abstract}

\title{
Keywords
}

Isolated mini-grid, optimization, mixed-integer linear programming, photovoltaic generation, solar irradiation.

\section{Resumen}

Este artículo presenta un nuevo modelo de programación lineal entera mixta que garantiza la solución óptima al problema de ubicación y dimensionamiento de generadores fotovoltaicos distribuidos, contemplando las curvas de radiación solar de cada nodo de las mini-redes aisladas y teniendo en cuenta como principal objetivo, minimizar las pérdidas de energía eléctrica en la operación del sistema. El modelo es de naturaleza no lineal, debido a que algunas restricciones no son lineales, sin embargo, en este artículo se propone utilizar técnicas de linealización para obtener un modelo lineal con una solución óptima global, el cual puede ser resuelto a través de analizadores de valor óptimo comerciales, para este trabajo se utilizó el solucionador comercial CPLEX. El modelo propuesto fue probado en una mini-red aislada de 14 nodos, basada en datos reales de topología, demanda y generación, adaptados a una operación balanceada. Este modelo, presenta como resultado la ubicación óptima de los generadores fotovoltaicos y su capacidad óptima dada por la máxima potencia activa entregada en el momento de máxima irradiación solar de la región. También se evidencia que la operación hibrida PCH-PV mejora el perfil de tensión de la red y las pérdidas de energía eléctrica sin la utilización de sistemas de almacenamiento de energía.

\section{Palabras clave}

Mini-red aislada, Optimización, programación lineal entera mixta, generación fotovoltaica, radiación solar. 


\section{Nomenclature}

These are the mathematical symbols used in this article for the mathematical models that are developed.

$\begin{array}{ll}\text { SHPP } & \text { Small hydroelectric power plants } \\ P V & \text { Photovoltaic generation } \\ \text { Sets: } & \\ \Omega_{i} & \text { Set of nodes } \\ \Omega_{g} & \text { Set of nodes with SHPP generation } \\ \Omega_{l} & \text { Set of lines } \\ \Omega_{t} & \text { Set of time intervals }\end{array}$

\section{Variables:}

$\Delta_{i j, t, Y}^{P} \quad$ Value of y-th block of $P_{i j, t}[\mathrm{~kW}]$

$\Delta_{i j, t, Y}^{Q} \quad$ Value of y-th block of $Q_{i j, t}[\mathrm{kVAr}]$

$I_{i j, t} \quad$ Magnitude of current in line $i j$ in time interval $t[\mathrm{~A}]$

$\vec{I}_{i j, t} \quad$ Phasor of the power flow in line $i j$ in time interval $t[\mathrm{~A}]$

$I_{i j, t}^{q d r} \quad$ Current magnitude squared on line $i j$ in time interval $t[\mathrm{~A}]$

$P_{i j, t} \quad$ Active power flow in circuit $i j$ in time interval $t[\mathrm{~kW}]$

$P_{i, t}^{S H P P} \quad$ Active power generated by the SHPP at node $i$ in time interval $t$ $[\mathrm{kW}]$

$P_{i, t}^{P V} \quad$ Active photovoltaic power generated at node $i$ in time interval $t[\mathrm{~kW}]$

$P_{i j, t}^{+}, P_{i j, t}^{-} \quad$ Non-negative auxiliary variables used in model $\left|P_{i j, d}\right|[\mathrm{kW}]$

$Q_{i j, t} \quad$ Reactive power flow in circuit $i j$ in time interval $t[\mathrm{kVAr}]$

$Q_{i, t}^{S H P P} \quad$ Reactive power generated by the SHPP at node $i$ in time interval $t$ [kVAr]

$Q_{i, t}^{P V} \quad$ Reactive photovoltaic power generated at node $i$ in time interval $t$ [kVAr]

$Q_{i j, d}^{+}, Q_{i j, d}^{-}$Non-negative auxiliary variables used to model $\left|P_{i j, d}\right|[\mathrm{kVAr}]$

$S_{i, t}^{S H P P} \quad$ Apparent power generated by SHPP at node $i$ in time interval $t[\mathrm{kVA}]$

$\bar{S}_{i}^{P V} \quad$ Apparent power rating of the $\mathrm{PV}$ generation set at node $i[\mathrm{kVA}]$

$S_{i, t}^{P V} \quad$ Apparent power generated by the $\mathrm{PV}$ generation system at node $i$ in time interval $t[\mathrm{kVA}]$

$\vec{V}_{i, t} \quad$ Voltage phasor at node $i$ in time interval $t[\mathrm{kV}]$

$V_{i, t}^{q d r} \quad$ Voltage magnitude squared at node $i$ in time interval $t[\mathrm{kV}]$

$X_{i}^{p v} \quad$ PV binary variable (there is generation or not at node $i$ ).

\section{Parameters:}

$\bar{\Delta}_{i j}^{s} \quad$ Upper limit of each block of linearizations

$\overline{f p}_{i}^{S H P P}$

${\underline{f p_{i}^{S H P P}}}^{S H}$

$\overline{f p}_{i}^{P V}$

$\underline{f p_{i}^{P V}}$

$\bar{I}_{i j}$

$m_{i j, y}^{S}$

$N p$

$P_{i, t}^{D}$

$Q_{i, t}^{D}$

$R_{i j}$

$R S_{i, t}^{p v}$

$\bar{S}_{i}^{S H P P}$

$S_{i, t}^{\max . P V}$

Maximum power factor of the generation in the SHPP at node $i$

Minimum power factor of the generation in the SHPP at node $i$

Maximum power factor of the PV generation at node $i$

Minimum power factor of the PV generation at node $i$

Maximum limit of the magnitude of the current in the line $i j[\mathrm{~A}]$

Slope of the $y$-th block of the piecewise linearization on the line $i j$

Maximum number of PV generators

Active demand power at node $i$ in time interval $t[\mathrm{~kW}]$

Reactive power of demand at node $i$ in time interval $t$

Line resistance $i j[\mathrm{kVAr}]$

Solar irradiation at node $i$ in time interval $t\left[\mathrm{~kW} / \mathrm{m}^{2}\right]$

Apparent power rating of the SHPP at node $i[\mathrm{kVA}]$

Maximum apparent power of each $\mathrm{PV}$ at node $i$ in time interval $t$ [kVA]

$S_{i, t}^{\text {min.PV }} \quad$ Minimum apparent power of each $\mathrm{PV}$ at node $i$ in time interval $t$ [kVA]

$\bar{V} \quad$ Maximum permissible value of the voltage magnitude $[\mathrm{kV}]$

V Minimum admissible value of the voltage magnitude $[\mathrm{kV}]$

$V^{\text {nom }} \quad$ Magnitude of voltage rating $[\mathrm{kV}]$

$X_{i j} \quad$ Line reactance $i j[\mathrm{Ohm}]$

$Y \quad$ Number of the linearization partitions

$Z_{i j} \quad$ Line impedance $i j[\mathrm{Ohm}]$ 


\section{INTRODUCTION}

Climate change is a phenomenon that aggravates health problems as well as the situation of flora and fauna threatened with extinction on all continents [1]. Burning fossil fuels to generate electric power increases those problems because greenhouse gases are released into the atmosphere. As a response, the global climate change agreement was signed in order to create strategies to reduce $\mathrm{CO} 2$ emissions by $20 \%$ by 2020 [2]. Consequently, the development and implementation of alternative energy sources was encouraged. For instance, photovoltaic generation, together with wind power generation, is one of the protagonists in the fight against global warming.

Photovoltaic generation accounts for $2 \%$ of the global demand, with around $303 \mathrm{GW}$ installed capacity in 2016 and a tendency to increase to $400 \mathrm{GW}$ by the end of 2017 . Since 2013, the development of the market of photovoltaic systems has been more consolidated because it is becoming the most economical option to generate electricity from technologies considered renewable [3].

At the end of 2015, Colombia also joined the project to reduce $20 \%$ of $\mathrm{CO} 2$ emissions by the year 2030 [4]. This initiative is regulated by Law 1715 of 2014 , Decree 2143 of 2015 issued by the Ministry of Mines and Power, resolution UPME 045 of 2016 and Resolution MADS 1283 of 2016 [5], which promote the integration of unconventional sources of renewable energies into the national interconnected system (SIN by its Spanish acronym) and their development in the isolated regions that do not receive the power supply from the SIN, known in Colombia as noninterconnected zones NIZ. NIZ represent $52 \%$ of the national territory, equivalent to 18 departments, 95 municipalities, 36 municipal seats and 5 department capitals [6] where hospitals, schools, and small industries can be found. These areas are typically powered by diesel and small hydroelectric power plants (SHPP).

In the NIZ, the aim is generally to complement the existing conventional generation through photovoltaic (PV) source projects [7], since Colombia has an average irradiation of $4.5 \mathrm{kWh} / \mathrm{m} 2 / \mathrm{d}$ throughout the year, surpassing the world's average of $3.9 \mathrm{kWh} / \mathrm{m} 2 / \mathrm{d}$, mainly due to the fact that this country does not have seasons [8].

The objective of complementing other energy sources is to make up for the growth in the demand and to enhance the quality of supply through efficient applications that allow the maximum use of the solar resource [7]. Hybrid systems such as solar-wind-diesel, solar-diesel and solar-wind have been implemented in PV generation projects developed in NIZ [9].

Because the power generated by means of PV sources depends on solar irradiation (which is an intermittent primary resource that depends on geographical location), methodologies that allow an adequate sizing and location of the photovoltaic panels should be proposed to guarantee an efficient operation of the network and maximum use of the solar resource [10], [11].

Currently, different studies address the problem of integrating PV generation into NIZ. Table 1 shows different works with techniques and optimization methods to determine the size and location of PVs sources. Some have taken into account the financial variables of the system, such as marginal prices due to location and congestion income, and prices and profitability of the PV with an annual flat rate of energy. Others have considered the load profile, power losses and voltage profiles of the electrical system. 
Location and optimal sizing of photovoltaic sources in an isolated mini-grid

Table 1. State of the art, sizing and optimal location of PVs. Source: Authors' own work.

\begin{tabular}{|c|c|c|c|c|c|c|c|c|}
\hline \multirow[b]{2}{*}{ Study } & \multirow[b]{2}{*}{ Method } & \multirow[b]{2}{*}{ Location } & \multirow[b]{2}{*}{ Size } & \multicolumn{5}{|c|}{ Restrictions } \\
\hline & & & & Costs & $\begin{array}{l}\text { Load } \\
\text { profile }\end{array}$ & Power losses & $\begin{array}{l}\text { Voltage } \\
\text { profiles }\end{array}$ & $\begin{array}{l}\mathrm{W} / \mathrm{m} 2 \\
\text { solar }\end{array}$ \\
\hline [13] & Optimization & $\mathrm{x}$ & $\mathrm{x}$ & $\mathrm{x}$ & & & & \\
\hline [10] & $\begin{array}{l}\text { Genetic algorithm + } \\
\text { search for patterns }\end{array}$ & & $\mathrm{x}$ & & $\mathrm{x}$ & & & \\
\hline$[14]$ & Swarm of particles & $\mathrm{x}$ & & $\mathrm{x}$ & & & & \\
\hline [15] & Genetic algorithm & & $\mathrm{x}$ & & & $\mathrm{x}$ & $\mathrm{x}$ & \\
\hline$[16]$ & Artificial intelligence & & $\mathrm{x}$ & $\mathrm{x}$ & $\mathrm{x}$ & & & \\
\hline [11] & $\begin{array}{l}\text { Multi-objective index } \\
\text { method (IMO) }\end{array}$ & & $\mathrm{x}$ & & & $\mathrm{x}$ & $\mathrm{x}$ & \\
\hline This work & MILP & $\mathrm{x}$ & $\mathrm{x}$ & & & $\mathrm{x}$ & $\mathrm{x}$ & $\mathrm{x}$ \\
\hline
\end{tabular}

Most works included in Table 1 propose methods to optimize the size of the PV source in isolated regions; however, they do not consider additional distributed generation (DG) and their convenient location and, when they do, they analyze the prices and costs of the system without taking into account solar irradiation in different regions.

This study proposes a mixed integer linear programming model (MILP) for the location and optimal sizing of PV generators in an isolated mini-grid that includes SHPPs. The mathematical model is obtained by applying linearization techniques to a mixed integer nonlinear programming model (MINLP).

The objective function is to minimize the electrical losses of the mini-grid, guaranteeing an efficient operation between the conventional existing DG and the proposed PV generation in order to satisfy the demand of the system. In addition, the solar irradiation of each possible location of the panels is considered. The model was written in a mathematical programming language (AMPL) and the solution was found using commercial tools to solve MILP problems.

The proposed model was evaluated in an isolated mini network based on an actual distribution system in the region of Caldas, Colombia. Such model considers curves of solar radiation from each isolated node in the mini-grid nodeto determine the generation capacity of the PVs system that will be included into the system. Our results show that the incorporation of $\mathrm{PV}$ sources decreases power losses and improves the voltage profile of the system, which proves that the proposed model can be applied to calculate, in a robust way, the location and capacity of multiple PV generators in isolated mini-grids that include SHPPs.

This document is structured as follows: Section 2 describes the MILP methodology, as well as the mathematical model for the isolated mini-grid, the SHPPs and the PVs, the function of solar irradiation and the characteristics of the isolated mininetwork study case. Section 3 discusses the results of the implemented model. Section 4 presents the conclusions, and the acknowledgments are found in Section 5.

\section{METHOD}

Different optimization problems are classified by the nature of the objective function, the constraints and the variables that are part of the programming model [12]. Thus, the nature of an objective function can be linear, convex or nonlinear; in the case of constraints, they can be linear, non-linear or have no restrictions; and their variables can be continuous or discrete. Table 2 lists different programming problems. 
The mathematical model for the operation of the isolated mini-grid contains several continuous variables, such as power flows in the lines, magnitude, and angle of the voltage at nodes. In addition, to determine the location and optimal capacity of the PVs sources, different variables should be considered; they include the injection of active and reactive power of the distributed generators (continuous variables), the existence or not of $\mathrm{PV}$ generators in each node of the electrical system (binary variable), and the maximum peak power of each PV source (continuous variable). The model in this work implements both continuous and discrete variables, which makes it a mixedinteger programming model.

\subsection{Mathematical model for the operation of the isolated mini-grid}

The following considerations are taken into account for the operation in permanent regime of the distribution system (DS): loads are represented as constant active and reactive powers that satisfy a demand function in each node, active and reactive power losses in circuit $i j$ are concentrated oat node $i$, and the DS is balanced and represented by a singlephase equivalent, as shown in Fig. 1 [17].

\subsubsection{Objective function and operation of the distribution system}

The selected objective function is to minimize the losses of the DS, as shown in (1), so that the operation of the isolated mini-grid provides a better quality of service and greater power consumption efficiency.

$\min$ losses $=\sum_{i j \in \Omega_{l}} R_{i j} I_{i j, t}^{q d r}$

The optimization model is subject to the operation of the DS in Fig. 1. Therefore, (2) and (3) mathematically describe the active and reactive power balance in each node, (4) formulate Kirchhoff's second law (the net electromotive force around a closed circuit loop is equal to the sum of potential drops around the loop), and (5) presents the relation among voltages, currents and powers [17].

The operation of the system is subject to the non-negative values of the voltage and current magnitude (6) and (7), to the restriction of maximum and minimum voltage magnitude at nodes, and to the maximum current the conductors of the existing distribution networks (8) and (9) can withstand.

Table 2. Optimization programming classification. Source: Compiled by the authors based on SH Bazaraa MS,

\begin{tabular}{|c|c|c|c|c|c|c|c|c|}
\hline \multirow[b]{2}{*}{ Programming problem } & \multicolumn{3}{|c|}{ Objective function } & \multicolumn{2}{|c|}{ Restriction } & \multicolumn{2}{|c|}{ Variables (and/or) } & \multirow[b]{2}{*}{$\begin{array}{l}\text { Characteristic } \\
\text { of the solution }\end{array}$} \\
\hline & Linear & $\begin{array}{c}\text { Non } \\
\text { linear }\end{array}$ & Convex & Linear & $\begin{array}{c}\text { No } \\
\text { lineal }\end{array}$ & Continuous & Discrete & \\
\hline Linear -LP & $\mathrm{x}$ & & & $\mathrm{x}$ & & $\mathrm{x}$ & & $\begin{array}{c}\text { Global } \\
\text { optimal }\end{array}$ \\
\hline Mixed integer linear- MELP & $\mathrm{x}$ & & & $\mathrm{x}$ & & $\mathrm{x}$ & $\mathrm{x}$ & $\begin{array}{c}\text { Global } \\
\text { optimal }\end{array}$ \\
\hline Nonlinear - NLP & & $\mathrm{x}$ & & $\mathrm{x}$ & & $\mathrm{x}$ & & Local \\
\hline Quadratic - QP & $\mathrm{x}$ & & $\mathrm{x}$ & $\mathrm{x}$ & $\mathrm{x}$ & $\mathrm{x}$ & & $\begin{array}{c}\text { optimal } \\
\text { Global } \\
\text { optimal }\end{array}$ \\
\hline $\begin{array}{l}\text { Mixed integer nonlinear - } \\
\text { MINLP }\end{array}$ & $x$ & $\underline{\mathrm{x}}$ & & $\mathrm{x}$ & & $\frac{\mathrm{x}}{\mathrm{x}}$ & $\frac{\mathrm{x}}{\mathrm{x}}$ & $\begin{array}{c}\text { Local } \\
\text { optimal }\end{array}$ \\
\hline
\end{tabular}




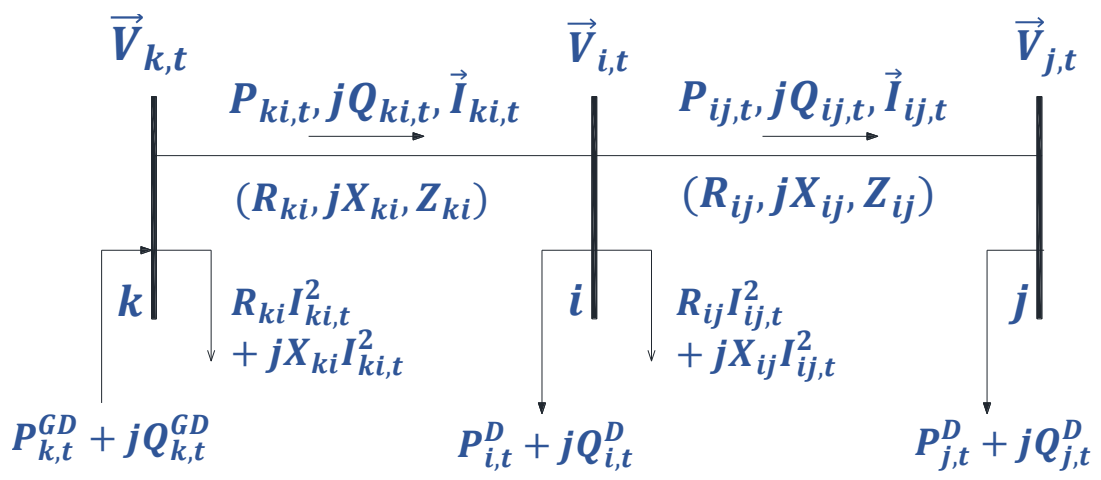

Fig. 1. Variables considered in the operation of the distribution system. Source: R. R. Gonçalves, J. F. Franco, and M. J. Rider.

\subsubsection{Mathematical model of the DG}

This model is established for both the PV generator and the SHPP. Continuous variables of the active power are determined $\left(P_{i, t}^{P V}, P_{i, t}^{S H P P}\right)$ and reactive power $\left(Q_{i, t}^{P V}, Q_{i, t}^{S H P P}\right)$ delivered by each DG located at node $i$, in the time interval $t$.
The maximum apparent power $\left(\bar{S}_{i}^{P V}, \bar{S}_{i}^{S H P P}\right)$ and the lower limit of the power factor $\left(f p_{i}^{P V}, f p_{i}^{S H P P}\right)$ of each DG at node $i$ are considered. This is shown in Fig. 2 and (10) to (15).

$$
\begin{aligned}
& \sum_{k i \in \Omega_{l}} P_{k i, t}-\sum_{i j \in \Omega_{l}}\left(P_{i j, t}+R_{i j} I_{i j, t}^{q d r}\right)+P_{i, t}^{S H P P}+P_{i, t}^{P V}=P_{i, t}^{D} \quad \forall i \in \Omega_{i}, \forall t \in \Omega_{t} \\
& \sum_{\mathrm{ki} \in \Omega_{1}} \mathrm{Q}_{\mathrm{ki}, t}-\sum_{\mathrm{ij} \in \Omega_{1}}\left(\mathrm{Q}_{\mathrm{ij}, t}+\mathrm{X}_{\mathrm{ij}} \mathrm{I}_{\mathrm{ij}, t}^{\mathrm{qdr}}\right)+Q_{\mathrm{i}, t}^{S H P P}+Q_{\mathrm{i}, t}^{P V}=\mathrm{Q}_{\mathrm{i}, \mathrm{t}}^{\mathrm{D}} \quad \forall i \in \Omega_{i}, \forall t \in \Omega_{t} \\
& V_{i, t}^{q d r}-2\left(R_{i j} P_{i j, t}+X_{i j} Q_{i j, t}\right)-Z_{i j}^{2} I_{i j, t}^{q d r}-V_{j, t}^{q d r}=0 \quad \forall i j \in \Omega_{\mathrm{l}}, \forall t \in \Omega_{t} \\
& I_{i j, t}^{q d r} V_{j, t}^{q d r}=P_{i j, t}^{2}+Q_{i j, t}^{2} \quad \forall i j \in \Omega_{\mathrm{l}}, \forall t \in \Omega_{t} \\
& 0 \leq \mathrm{I}_{\mathrm{ij}, t}^{\mathrm{qdr}} \quad \forall i j \in \Omega_{l}, \forall t \in \Omega_{t} \\
& 0 \leq \mathrm{V}_{\mathrm{j}, t}^{\mathrm{qdr}} \quad \forall i \in \Omega_{l}, \forall t \in \Omega_{t} \\
& \underline{V}^{2} \leq V_{i, d}^{q d r} \leq \bar{V}^{2} \quad \forall i \in \Omega_{i}, \forall \mathrm{t} \in \Omega_{t}
\end{aligned}
$$




$$
0 \leq I_{i j, d}^{q d r} \leq \bar{I}_{i j}^{2} \quad \forall i j \in \Omega_{l}, \forall \mathrm{t} \in \Omega_{t}
$$

\section{Model of the PV generator}

$$
\begin{aligned}
& \left(P_{i, t}^{P V}\right)^{2}+\left(Q_{i, t}^{P V}\right)^{2}=\left(S_{i, t}^{P V}\right)^{2} \forall i \in \Omega_{i}, \quad \forall t \in \Omega_{t} S_{i, t}^{P V} \leq \bar{S}_{i}^{P V} \quad \forall i \in \Omega_{i}, \forall t \in \Omega_{t} \\
& 0 \leq P_{i, t}^{P V} \quad \forall i \in \Omega_{i}, \forall t \in \Omega_{t} \\
& -P_{i, t}^{P V} \tan \left(\cos ^{-1}\left(\underline{f p}_{i}^{P V}\right)\right) \leq Q_{i, t}^{P V} \leq P_{i, t}^{P V} \tan \left(\cos ^{-1}\left(\overline{f p}_{i}^{P V}\right)\right) \quad \forall i \in \Omega_{i}, \forall t \in \Omega_{t}
\end{aligned}
$$

\section{Model of the SHPP generator}

$$
\begin{aligned}
& \left(P_{i, t}^{S H P P}\right)^{2}+\left(Q_{i, t}^{S H P P}\right)^{2}=\left(S_{i, t}^{S H P P}\right)^{2} \forall i \in \Omega_{g}, \forall t \in \Omega_{t} * \\
& S_{i, t}^{S H P P} \leq \bar{S}_{i}^{S H P P} \quad \forall i \in \Omega_{g}, \forall t \in \Omega_{t} \\
& 0 \leq P_{i, t}^{S H P P} \quad \forall i \in \Omega_{g}, \forall t \in \Omega_{t} \\
& -P_{i, t}^{S H P P} \tan \left(\cos ^{-1}\left(\underline{f p}_{i}^{S H P P}\right)\right) \leq Q_{i, t}^{S H P P} \leq P_{i, t}^{S H P P} \tan \left(\cos ^{-1}\left(\overline{f p}_{i}^{S H P P}\right)\right) \quad \forall i \in \Omega_{g}, \forall t \in \Omega_{t}
\end{aligned}
$$

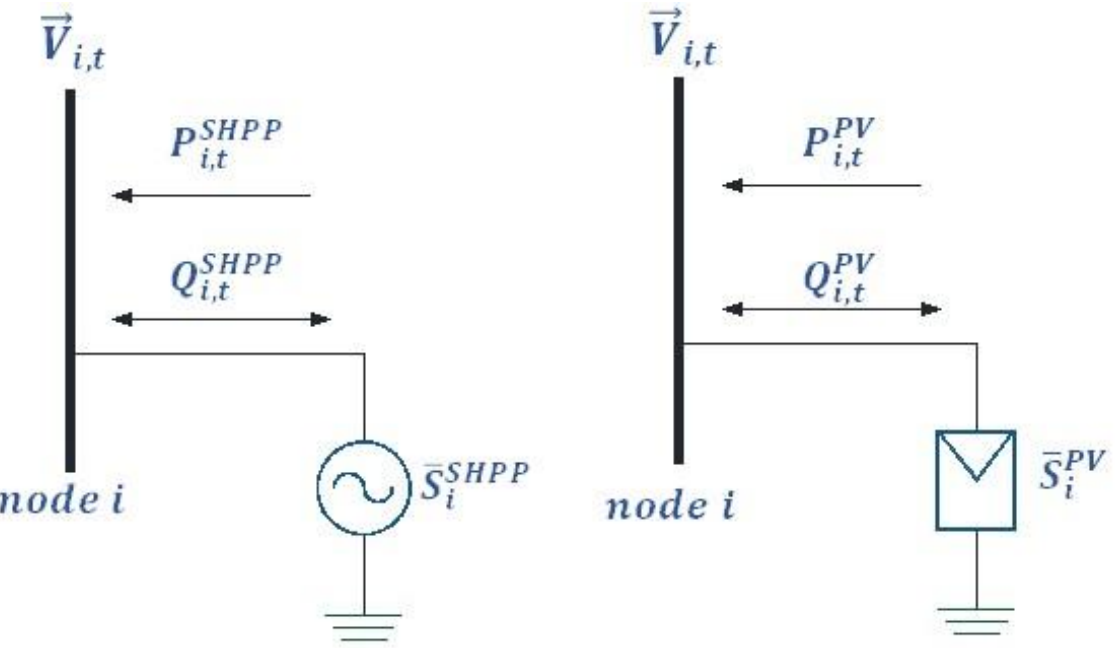

Fig. 2. DG model in node $i$. Source: Authors' own work. 
Expressions (10) and (13) present the definition of apparent power depending on the active and reactive power produced by the PV and SHPP generators, respectively. Equations (10) and (13) are different because $\bar{S}_{i}^{S H P P}$ is a parameter that indicates the nominal power of the SHPP, a value that is taken from the isolated mini-grid to be studied, and $\bar{S}_{i}^{P V}$ is a variable that defines the nominal power of each PV generator based on the corresponding solar radiation curve. In these equations, $S_{i, t}^{S H P P}$ and $S_{i, t}^{P V}$ must not exceed the maximum power defined at node $i$ for distributed generation. In (11) and (14) the generated power must be positive, and (12) and (15) define the limits of the maximum and minimum power factor of the SHPPs and the inverters that connect the PV generators to the DS.

The main contribution of this model can be observed in (16), which determines that the power generated by the PV system, $S_{i, t}^{P V}$, is a function of the nominal power of the generation set $\bar{S}_{i}^{P V}$ of the solar irradiation of each area $\operatorname{RS}_{i, t}^{P V}$ and the binary decision variable $\boldsymbol{X}_{\boldsymbol{i}}^{P V}$, which locates the PV in node $i$. In turn, (16) limits the number of panels to be installed.

Expressions (5), (10), (13) and (16) are non-linear constraints; therefore, the problem is determined by a MINLP model,

$$
\begin{array}{ll}
P_{i j, t}^{+}-P_{i j, t}^{-}=P_{i j, t} & \forall i j \in \Omega_{l}, \forall t \in \Omega_{t} \\
P_{i j, t}^{+}+P_{i j, t}^{-}=\sum_{y=1}^{y} \Delta_{i j, t, y}^{P} & \forall i j \in \Omega_{l}, \forall t \in \Omega_{t} \\
Q_{i j, t}^{+}-Q_{i j, t}^{-}=Q_{i j, t} & \forall i j \in \Omega_{l}, \forall t \in \Omega_{t} \\
Q_{i j, t}^{+}+Q_{i j, t}^{-}=\sum_{y=1}^{y} \Delta_{i j, t, y}^{Q} & \forall i j \in \Omega_{l}, \forall t \in \Omega_{t}
\end{array}
$$

as highlighted with the green box in Table 2.

$$
\begin{aligned}
& S_{i, t}^{P V}=\bar{S}_{i}^{P V} R S_{i, t}^{P V} \boldsymbol{X}_{i}^{P V} \\
& \forall i \in \Omega_{i}, \forall t \in \Omega_{t} * \\
& \sum_{i \in \Omega_{l}} X_{i}^{P V} \leq N p \quad \forall i \in \Omega_{l}
\end{aligned}
$$

\subsection{Linearization of the mixed-integer non- linear programming problem}

The overall optimal response can be obtained by means of a convex problem. Below is the linearization of (5), (10), (13) and (16) to form a MILP model, shown in the red box of Table 2 .

\subsubsection{Linearization of the power model of the network state}

The relation among voltages, currents and powers in (5) may be linearized through discretization blocs. Fig. 3 shows the way a non-linear function can be expressed using several lines $Y$ of different slope, and that the accuracy of the function varies depending on the number of the discretization (the value that $Y$ adopts). Then, (5) is defined by means of an additional number of linear constraints and continuous variables, as shown in (17)-(28) [18]. 


$$
\begin{aligned}
& 0 \leq \Delta_{i j, t, y}^{P} \leq \bar{\Delta}_{i j}^{s} \quad \forall i j \in \Omega_{l}, y=1 \ldots Y, \forall t \in \Omega_{t} \\
& 0 \leq \Delta_{i j, t, y}^{Q} \leq \bar{\Delta}_{i j}^{S} \\
& \forall i j \in \Omega_{l}, y=1 \ldots Y, \forall t \in \Omega_{t} \\
& 0 \leq P_{i j, t}^{+} \quad \forall i j \in \Omega_{l}, \forall t \in \Omega_{t} \\
& 0 \leq P_{i j, t}^{-} \quad \forall i j \in \Omega_{l}, \forall t \in \Omega_{t} \\
& 0 \leq Q_{i j, t}^{+} \quad \forall i j \in \Omega_{l}, \forall d \in \Omega_{t} \\
& 0 \leq Q_{i j, t}^{-} \quad \forall i j \in \Omega_{l}, \forall t \in \Omega_{t} \\
& m_{i j, y}^{s}=(2 y-1) \bar{\Delta}_{i j}^{s} \quad \forall i j \in \Omega_{l}, y=1 \ldots Y \\
& \bar{\Delta}_{i j}^{s}=\frac{V^{n o m}}{\bar{I}_{i j}} \quad \forall i j \in \Omega_{l}
\end{aligned}
$$

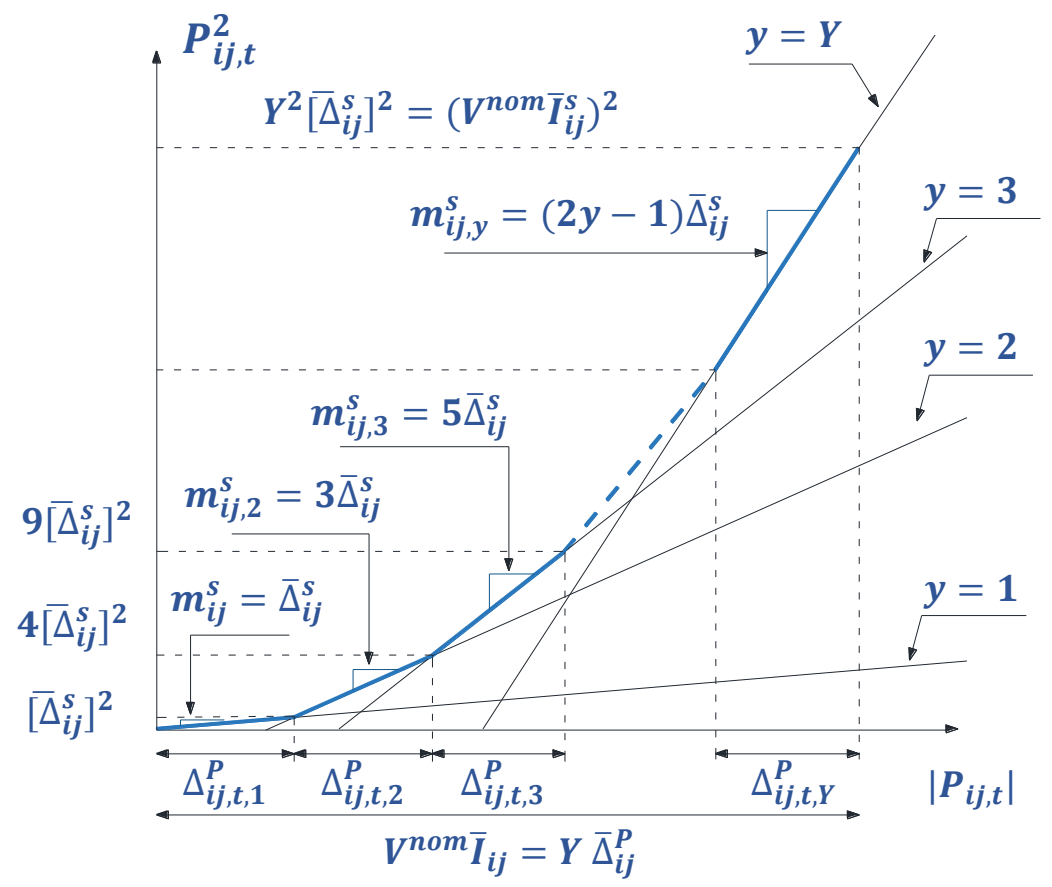

Fig. 3. Plot of a linearization. Source: J.F. Franco, M.J. Rider, M. Lavorato and R. Romero.

[70] TecnoLógicas, ISSN-p 0123-7799 / ISSN-e 2256-5337, Vol. 22, No. 44, enero-abril de 2019, pp. 61-80 


\subsubsection{Linearization of the DG}

Power model:

Expressions (10) and (13) may be replaced by inequations (29) and (30), respectively, which represent the conical formulation of the non-linear expression, thus generating a convex problem [19]

Location and sizing of PV generators:

The differentiating contribution of this work is given by restriction (16), which may be linearized and expressed with inequalities (31)-(34) through the application of the disjunctive formulation and [20] the help of auxiliary variables $S_{i, t}^{\max . P V} \mathrm{Y} S_{i, t}^{\min . P V}$

Finally, the MILP model is described in (1)-(4), (6)-(9), (11)-(12), (13)-(15), and (16)-(34).

\subsection{Solar radiation function}

The maximum power and performance of the PV generator depend on the solar irradiation of the region or area where it will be installed. The solar radiation curves data were taken from the database of the National University of Colombia for the year 2017; they were obtained from weather stations located in three different neighborhoods in Manizales, Colombia (namely, El Carmen, Aranjuez and Villamaría). To each system node,

$$
\begin{aligned}
& \left(P_{i, t}^{P V}\right)^{2}+\left(Q_{i, t}^{P V}\right)^{2} \leq\left(S_{i, t}^{P V}\right)^{2} \\
& \forall i \in \Omega_{i}, \forall t \in \Omega_{t} \\
& \left(P_{i, t}^{S H P P}\right)^{2}+\left(Q_{i, t}^{S H P P}\right)^{2} \leq\left(S_{i, t}^{S H P P}\right)^{2} \\
& \forall i \in \Omega_{i}, \forall t \in \Omega_{t} \\
& S_{i, t}^{P V} \geq S_{i, t}^{\text {min.PV }} R S_{i, t}^{P V} X_{i}^{P V} \\
& \forall i \in \Omega_{i}, \forall t \in \Omega_{t}
\end{aligned}
$$

indicated in Fig 5, the nearest solar radiation curve is assigned, according to Fig. 4.

\subsection{Technical characteristics of the isolated mini-grid for the study case}

The Proposed programming model is implemented in a mini-isolated network where all the nodes are possible candidates for the installation of PVs sources of any power. The isolated mini-grid operates at a nominal voltage at the distribution level $(13.2 \mathrm{kV})$, with a radial configuration, where the main power sources and consumers are connected through the distribution substations. The mini-grid implemented in this work consists of three SHPPs (Intermediate, Municipal and Sancancio) located in three nodes (3, 8, and 14, respectively). The capacity of the Intermediate and the Municipal SHPPs is $1 \mathrm{MW}$ each and Sancancio's reaches $2 \mathrm{MW}$; thus, the total generation capacity of this mini-grid is 4 MW. Fig. 5 presents the simplified one-line diagram of the study case. The system load is modelled through a typical demand curve of the average demand in the isolated mini-grid. In turn, Fig. 6 shows demand peaks between 10 a.m. and 12 p.m. and 6:30 p.m. and 8:30 p.m. because they are the time ranges with highest consumption in the system.

The variations in the daily deman shown in Fig. 6, especially at noon and at the end of work hours, show that users are predominantly residential [22]. 
$S_{i, t}^{P V} \leq S_{i, t}^{\max . P V} R S_{i, t}^{P V} X_{i}^{P V}$

$\forall i \in \Omega_{i}, \forall t \in \Omega_{t}$

$\bar{S}_{i}^{P V} R S_{i, t}^{P V}-S_{i, t}^{P V} \geq S_{i, t}^{\min . P V} R S_{i, t}^{P V}\left(1-X_{i}^{P V}\right)$

$\forall i \in \Omega_{i}, \forall t \in \Omega_{t}$

$\bar{S}_{i}^{P V} R S_{i, t}^{P V}-S_{i, t}^{P V} \leq S_{i, t}^{\max . P V}\left(1-X_{i}^{P V}\right)$

$\forall i \in \Omega_{i}, \forall t \in \Omega_{t}$

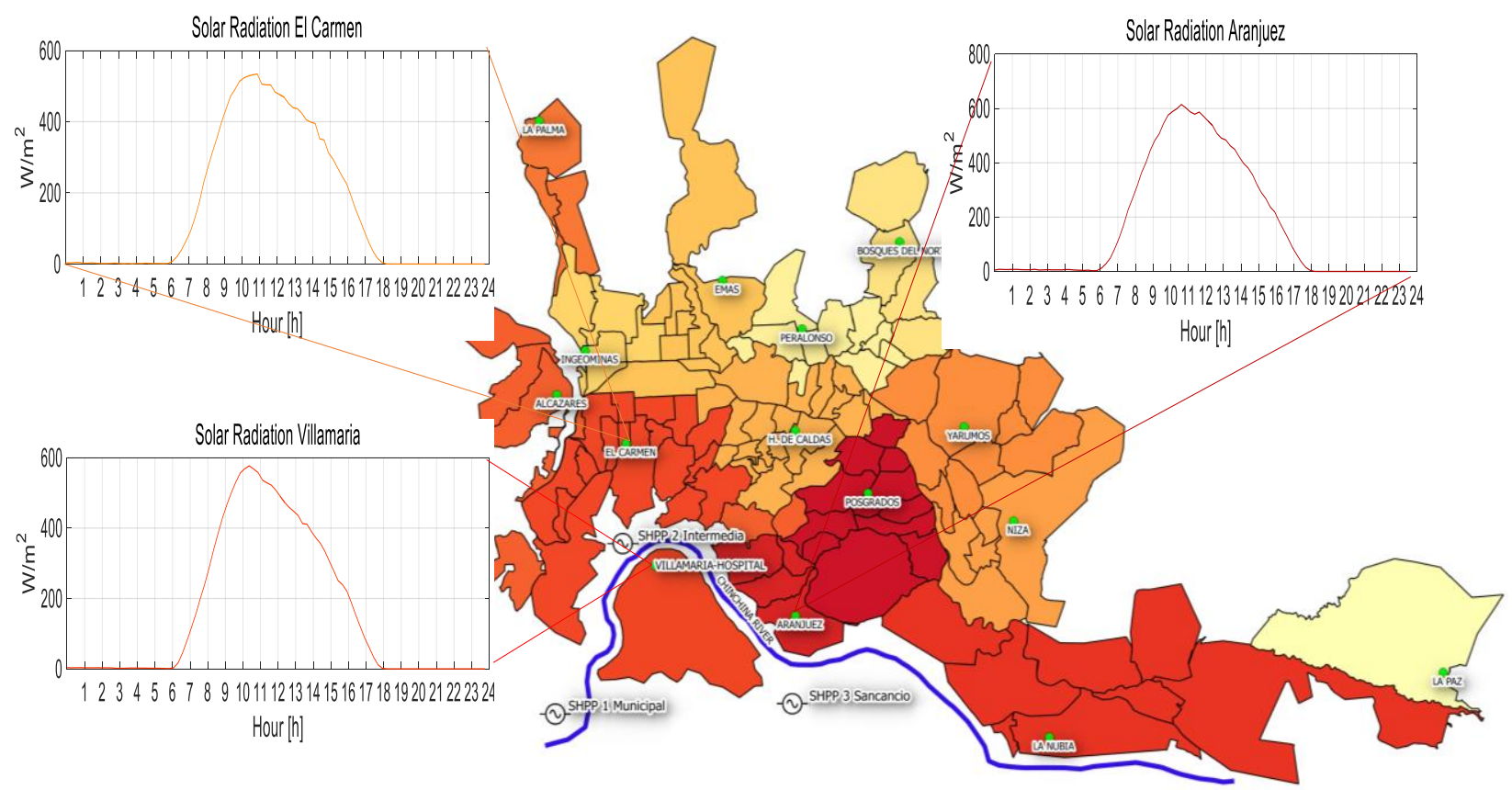

Fig. 4. Map of the region of Manizales and its weather stations. Source: Authors' own work.

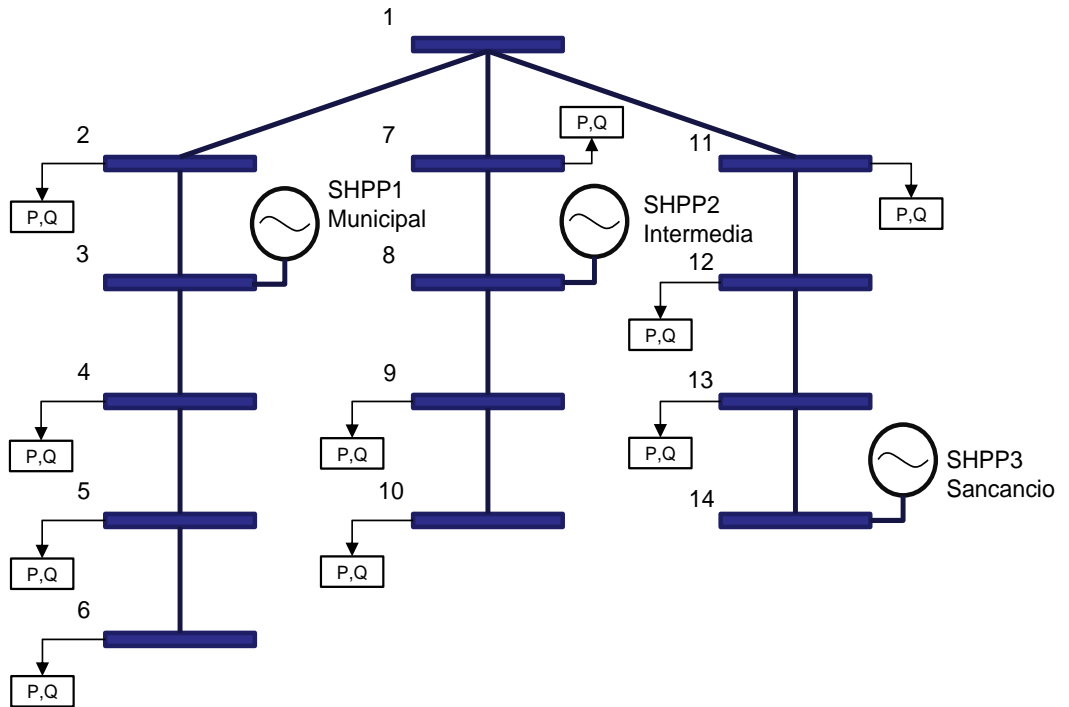

Fig. 5. Mini-grid with the location of three SHPPs. Source: Authors' own work.

[72] TecnoLógicas, ISSN-p 0123-7799 / ISSN-e 2256-5337, Vol. 22, No. 44, enero-abril de 2019, pp. 61-80 


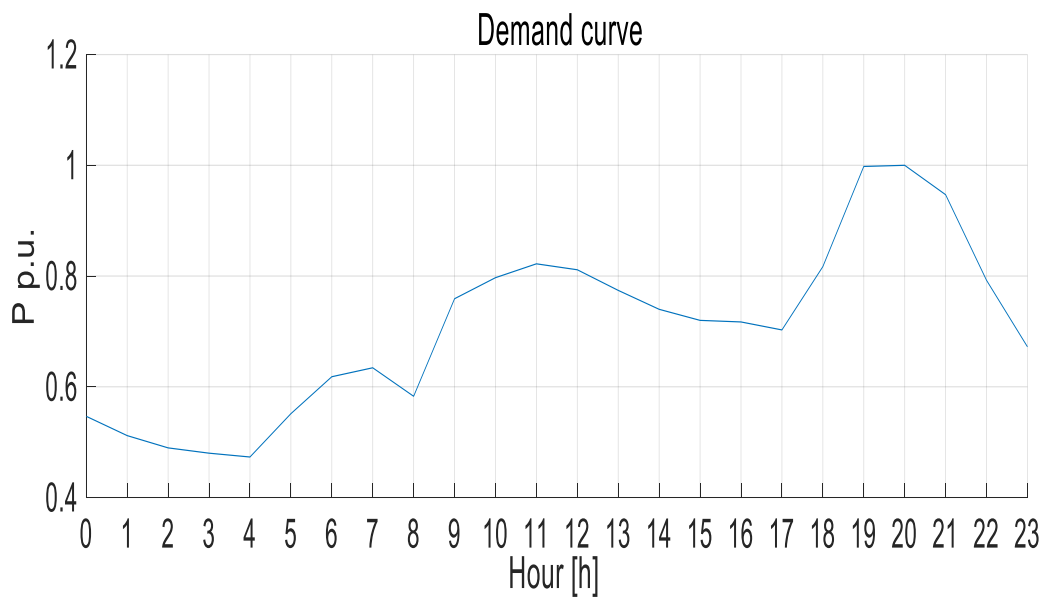

Fig. 6. Typical curve of average demand in a residential system. Source: CHEC, the company that operates the actual grid on which the model in this study is based.

\section{RESULTS: LOCATION AND OPTIMAL SIZING OF PVs sources}

The MILP model proposed in this work is formulated in the mathematical language AMPL and solved using the commercial Solver CPLEX. Fig. 7 shows the result of the MILP model: nodes 5, 10, and 12 were selected through the variable $X_{i}^{P V}$ to optimally locate the three $\mathrm{PVs}$ sources, with maximum powers of $779 \mathrm{kVA}$, $344 \mathrm{kVA}$ and $664 \mathrm{kVA}$, respectively, for the region of Manizales.

The output of the model reveals that the optimal location seeks to distribute the generators in a uniform way, prioritizing the nodes at the end of the circuit; accordingly, less energy transport is achieved by the same demand. This is a consequence of the minimization of system losses in the objective function.

\subsection{Optimal operation of PVs sources}

In order to determine the location and size of PV generators that enable to achieve optimal operation throughout the day, the model indicates the power each generator must deliver in each period of time according to the operating constraints (both for SHPPs and PVs) and the solar radiation curve of the area.

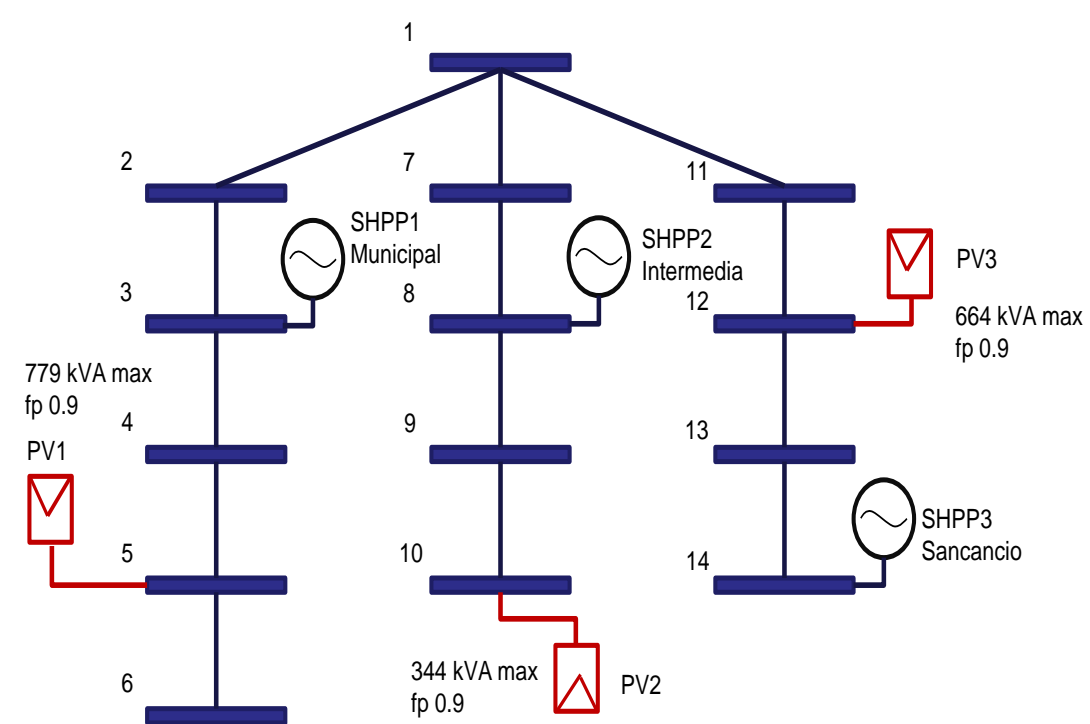

Fig. 7. Result of the location and optimal sizing of PV generators. Source: Authors' own work. 
Fig. 8 shows a comparison of the system's operation before and after the implementation of the PV generators. It can be seen that technical losses of electric power in the system are lower in the presence of PVs, a reduction of approximately $30 \%$, between 6 a.m. and 5 p.m.
Figs. 9a, 9b, 9c, and $9 \mathrm{~d}$ present the voltage profiles of nodes $2,6,11$ and 7 , respectively. These results show, in detail, a better voltage profile at the operating hours of the PV generators, both of the intermediate nodes and those at the end of the circuits. The resulting isolated minigrid provides a better quality power service when PVs are included in the DS.

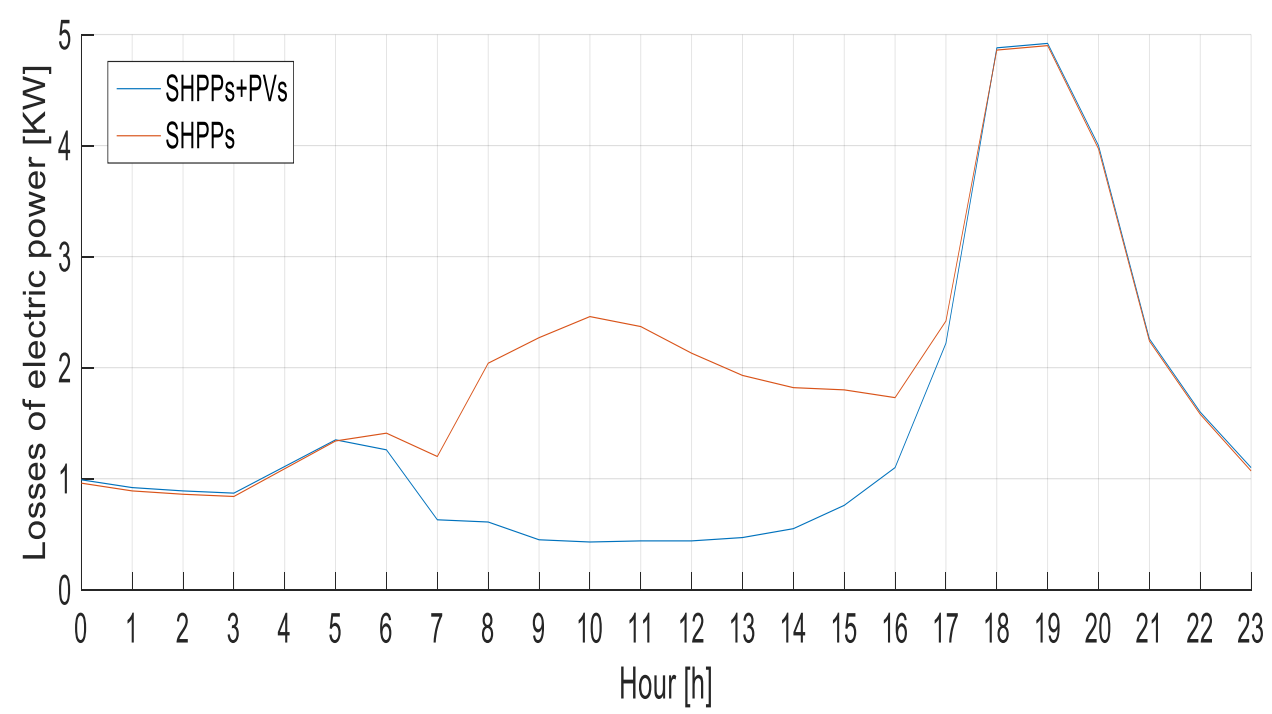

Fig. 8. Technical losses of electric power with and without PVs. Source: Authors' own work.

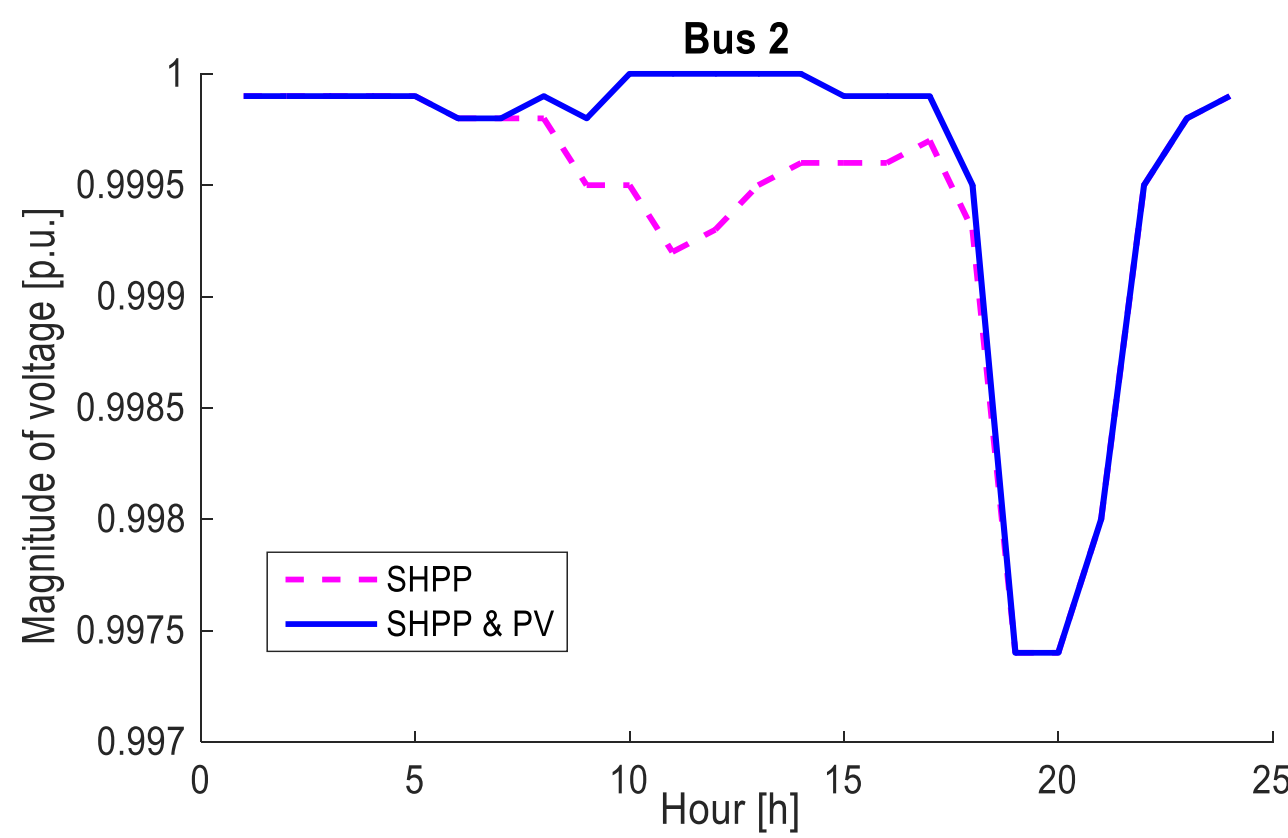

Fig. 9a. Voltage profile with and without PVs in node 2. Source: Authors' own work. 
Location and optimal sizing of photovoltaic sources in an isolated mini-grid

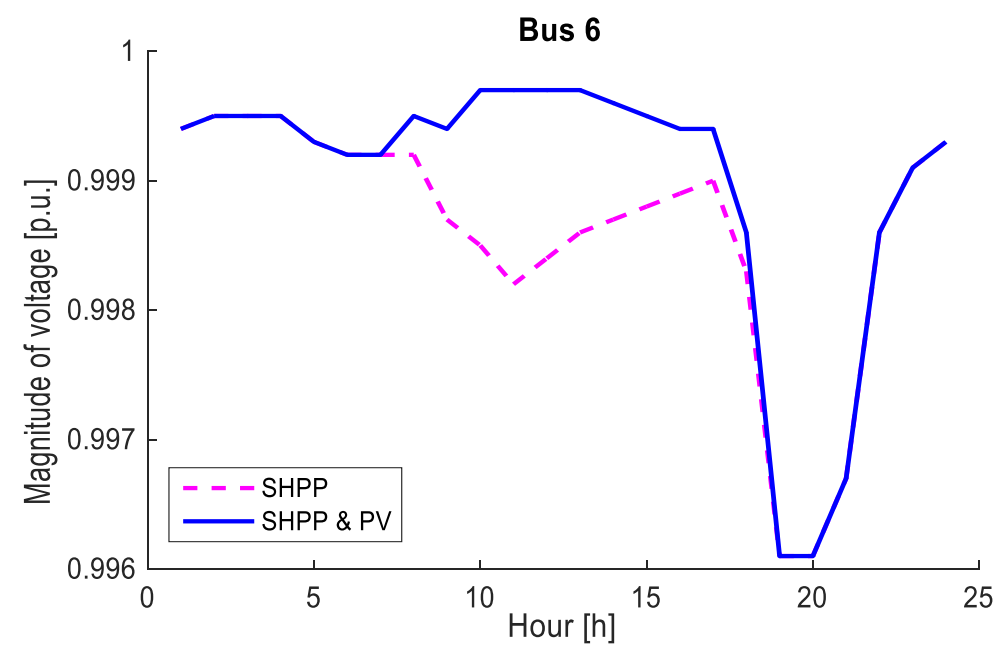

Fig. 9b. Voltage profile with and without PVs in node 6. Source: Authors' own work

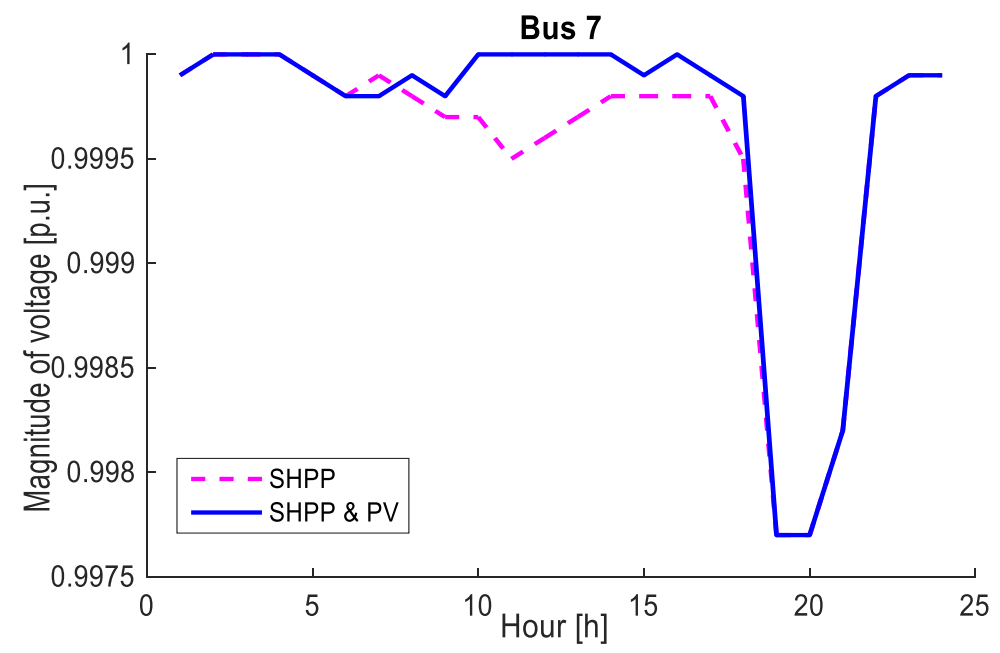

Fig. 9c. Voltage profile with and without PVs in node 7. Source: Authors' own work.

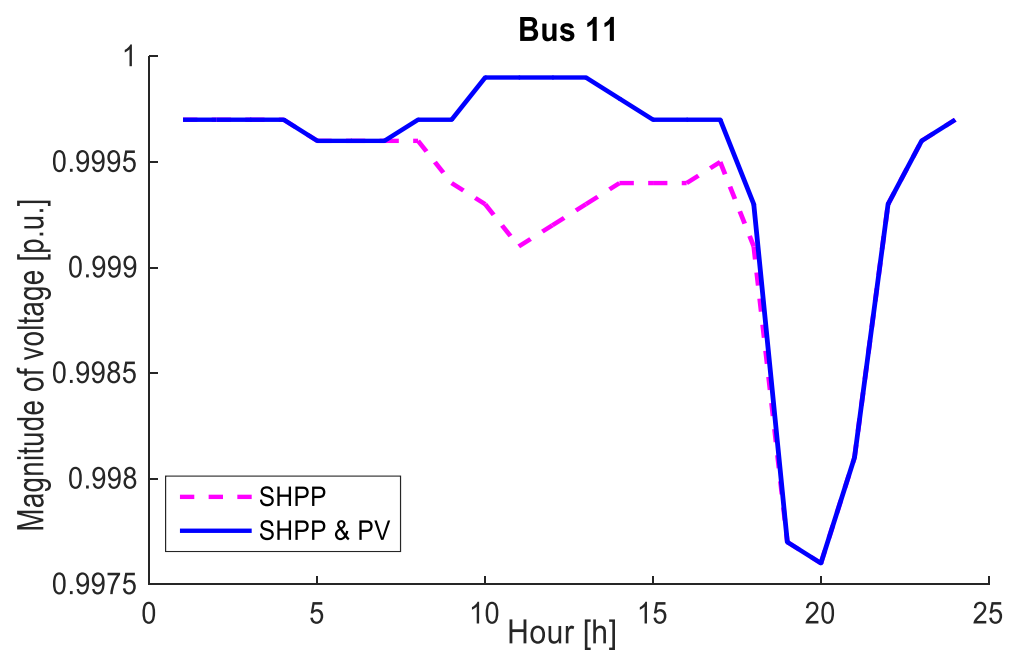

Fig. 9d. Voltage profile with and without PVs in node 11. Source: Authors' own work. 
Fig. 10 shows the optimal daily generation of active power with SHPPs and PVs, where PV generation participates in the power supply between 6 a.m. and 6 p.m. (which corresponds to the highest range of the solar irradiation curve in this area), without an important impact on the peak demand.

Fig. 11 shows the contribution of each SHPP (Intermediate, Municipal and the Sancancio), as well as the PV sources located in nodes 5, node10 and node 12 , which are responsible for meeting the active demand in the daily operation of the isolated mini-grid. Fig. 12 shows that the power delivered by the SHPP to node 14 is minimized between 10:00 a.m. and 03:00 p.m., supplying sufficient power with a low power factor to satisfy the reactive power demand of the system, since the inverters of the PV generators are limited to a power factor of 0.9 and, by themselves, they could not meet the demand for reactive power.

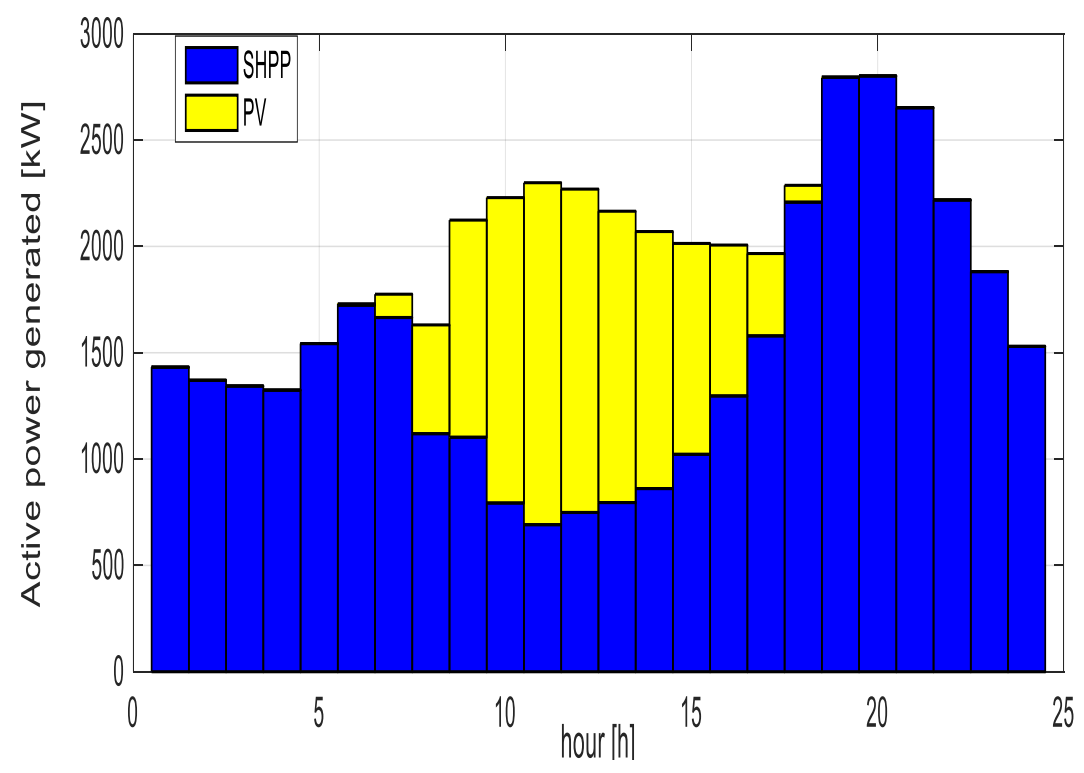

Fig. 10. Daily operation of the DG. Source: Authors' own work.

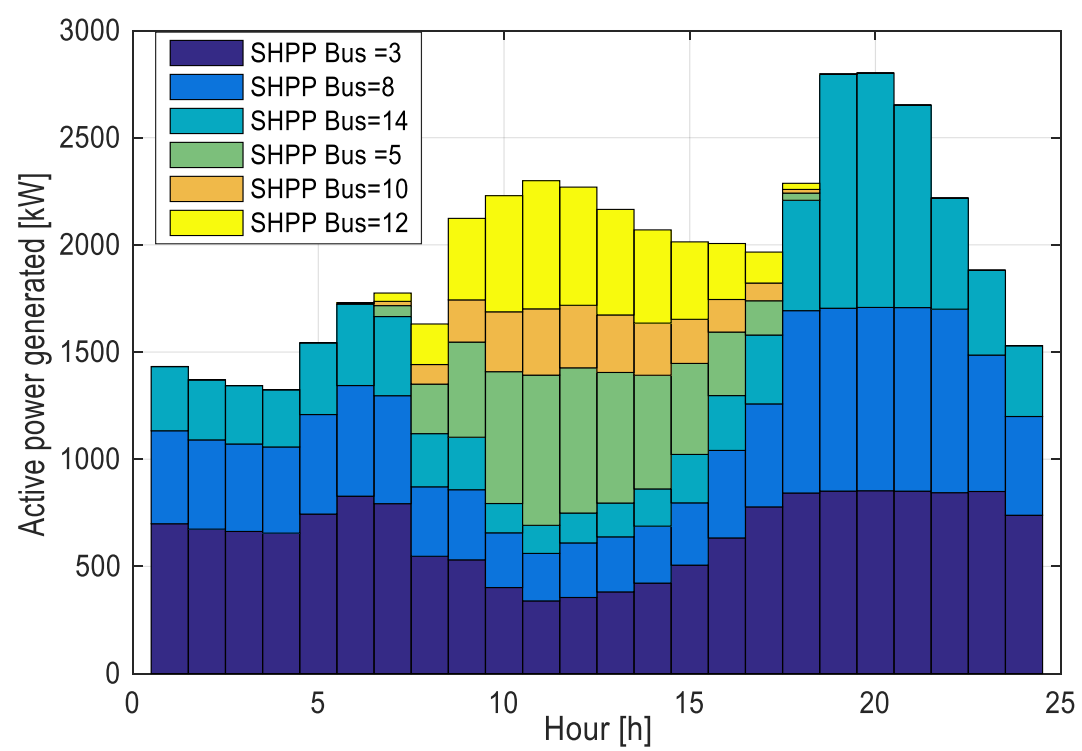

Fig. 11. Active power generated by specific SHPPs and PVs. Source: Authors' own work. 


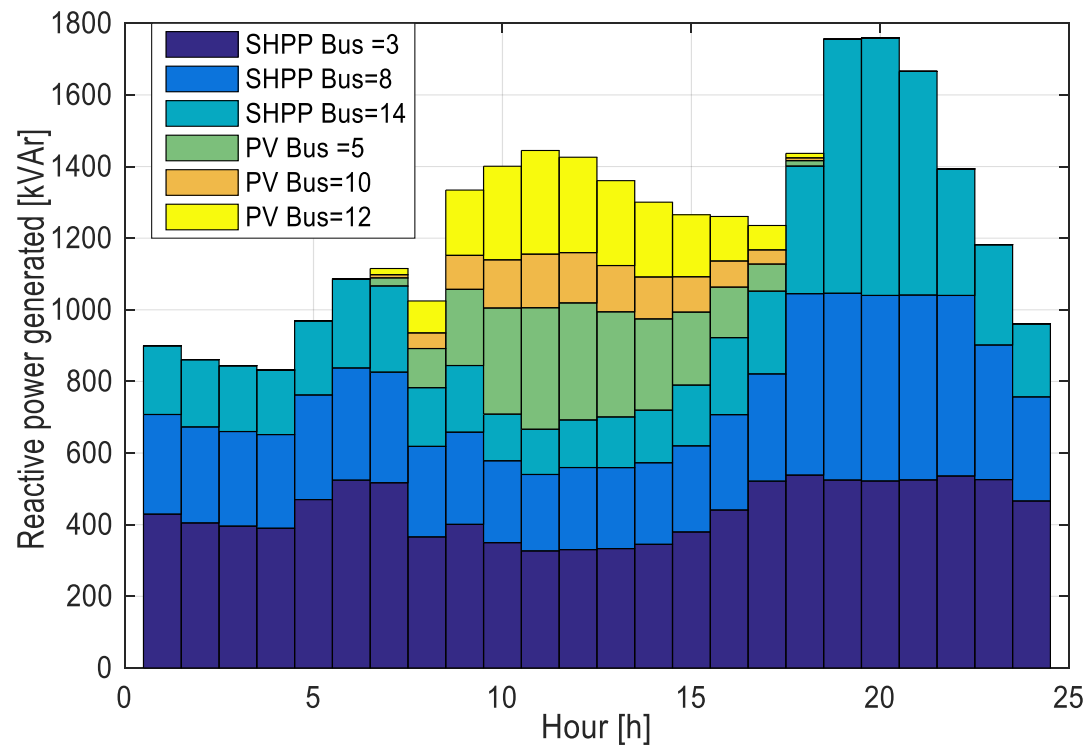

Fig. 12. Reactive power generated by specific SHPPs and PVs. Source: Authors' own work.

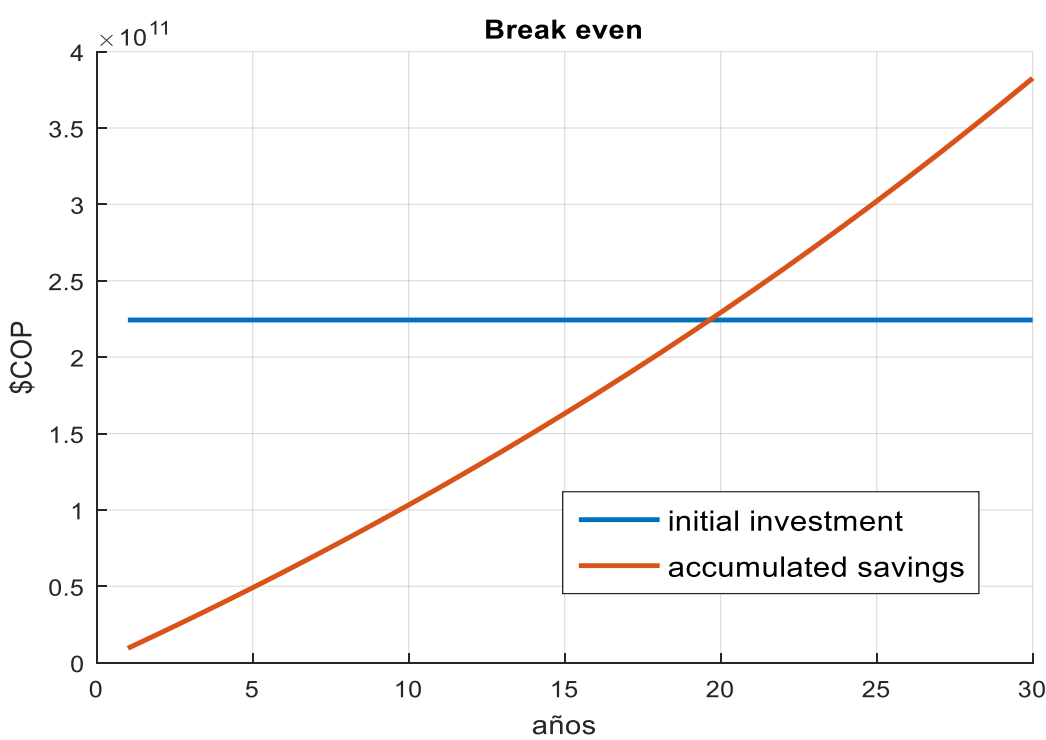

Fig. 13. Initial investment vs. accumulated savings. Source: Authors' own work.

The results of the simulations in Figs. 8-12 show that the optimal selection of the location and capacity of PV sources guarantees efficient loss reduction and the improvement of the voltage profile of each node in the DS. This is a consequence of minimizing the expression $R_{i j} I_{i j, t}^{q d r}$ in the objective function and considering the solar radiation curves of the areas of the DS branch circuits.

The solar radiation curves in the mathematical model enable to maximize the use of the solar resource, since the nodes that have the highest radiation incidence would be the Best candidates for the installation of PV generators. In addition, the model takes into account the isolated mini network's daily operation, and the contribution of each distributed generator is optimized considering the solar radiation curves and the demand function of the SD loads with a one-hour discretization. 


\section{COST ANALYSIS}

In order to analyze the financial feasibility of the proposed work, the following aspects are considered: cost of losses, initial investment in PV sources, and the operation and maintenance of the PV generation and SHPPs [23]. For that purpose, the return time of the initial investment is calculated taking into account the accumulated energy savings generated by the PV sources and additional savings due to a decrease in the system's losses.

Figure 13 shows an initial investment of 224.000 million COP that includes civil works, the cost of the panels and inverters, transport and construction. The savings that result from the difference between the costs of the energy generated by the $\mathrm{SHPPs}_{\mathrm{s}}(2,357 \mathrm{COP} / \mathrm{kWh})$ and PVs (276 $\mathrm{COP} / \mathrm{kWh}$, plus savings due to reduced losses $(14,528 \mathrm{COP} / \mathrm{kWh})$, enable to recover the investment in 20 years.

\section{CONCLUSIONS}

This article introduced a new mixedinteger linear programming model to solve the problem of locating and sizing the nominal capacity of $\mathrm{PV}$ generators in a mini-grid that includes SHPPs.

Battery Energy Storage Systems (BESS) were not included. However, the results show that the hybrid operation of SHPP-PV improves the voltage profile of the network and decreases power losses. The model is evidently efficient to select the nodes for PV generation, locating them near the end of the circuit. The selection of the capacity of each PV generator is determined by the maximum active power it can deliver to meet the demand at the time of maximum solar irradiation. Power capacity is, in turn, determined by the power factor of the inverter and the reactive power demand. The results show that the proposed method is efficient, and it can be used to solve the problems of locating and sizing the nominal capacity of PV generators.

The optimal daily operation of SHPPs and PVs (Fig. 10) shows that the residential demand curve has its highest peak between 6:30 p.m. and 8:30 p.m. Therefore, a set of BESS with PV generation systems must be considered so that the BESS contributes to meet the peak demand when the PV system is not in operation.

SHPPs and PV generation complement each other by adapting to the characteristics of the changing weather in Colombian NIZ and provide a sustainable system for these regions. Additionally, the power resources available in each zone should be considered to plan the electrical system of the NIZ.

Future works may include a mixed integer linear programming model for an unbalanced three-phase distribution system in order to obtain the optimal location and sizing of PV generation.

In order to obtain an optimal financial outcome, an economic analysis could also be applied to the proposed model so that its target function does not only consider the minimization of the cost of system losses but also the investment, operation and maintenance costs of the proposed generation solution plus the economic variables of the system.

\section{ACKNOWLEDGEMENTS}

The authors are grateful for the financial support of the Manizales Research Office (DIMA for its acronym in Spanish) of the National University of Colombia in Manizales through the project "Evaluation of the impact of the compensation for distributed generation and the demand for the provision of technical support services in the Colombian electrical distribution system" HERMES code 39039. 


\section{REFERENCES}

[1] W. N. Adger et al., "Human Security," in Climate Change 2014: Impacts, Adaptation, and Vulnerability, tergovernmental Panel on Climate Change, Ed. Intergovernmental Panel on Climate Change (IPCC), 2014, pp. 755-791.

[2] R. Fernández Reyes, "El Acuerdo de París y el cambio transformacional," Depósito Investig. Univ. Sevilla, no. 132, pp. 101-114, 2016.

[3] G. Masson and K. Izumi, "TRENDS 2017 IN PHOTOVOLTAIC APPLICATIONS Survey Report of Selected IEA Countries between 1992-2016," 2017.

[4] C. Gacía Arbelaéz, G. Vallejo, M. Lou Higgins, and E. M. Escobar, "El Acuerdo De París Así Actuará Colombia Frente $\mathrm{Al}$ Cambio Climático,” 2016.

[5] UPME, "Registro, Incentivos y Certificaciones. Fuentes no convencionales de energía - FNCE," UPME, 2018. [Online]. Available:

http://www1.upme.gov.co/Paginas/incentivosFNCE.aspx. [Accessed: 06-Apr-2018].

[6] IPSE, "Centro Nacional de Monitoreo," IPSEW, 2018. [Online]. Available: http://190.216.196.84/cnm/. [Accessed: 05Apr-2018].

[7] UPME, "Plan Energetico Nacional Colombia: Ideario Energético 2050," 2015.

[8] UPME, MINMINAS, BID, and fmam, "Integración de las energías renovables no convencionales en Colombia," 2015.

[9] E. E. Gaona, C. L. Trujillo, and J. A. Guacaneme, "Rural microgrids and its potential application in Colombia," Renew. Sustain. Energy Rev., vol. 51, pp. 125-137, Nov. 2015.

[10] V. Vermeulen, J. M. Strauss, and H. J. Vermeulen, "Optimisation of solar PV plant locations for grid support using genetic algorithm and pattern search," in 2016 IEEE International Conference on Power and Energy (PECon), 2016, pp. 72-77.

[11] D. Q. Hung, N. Mithulananthan, and R. C. Bansal, "Integration of PV and BES units in commercial distribution systems considering energy loss and voltage stability," Appl. Energy, vol. 113, pp. 1162-1170, Jan. 2014.

[12] M. S. Bazaraa, J. J. Jarvis, and H. D. Sherali, Linear Programming and Network Flows, 4th ed., no. 1. Wiley, 2011.

[13] M. Afkousi-Paqaleh, A. Abbaspour-Tehrani Fard, and M. Rashidinejad, "Distributed generation placement for congestion management considering economic and financial issues," Electr. Eng., vol. 92, no. 6, pp. 193-201, Nov. 2010.

[14] M. Gómez, F. Jurado, P. Díaz, and N. RuizReyes, "Evaluation of a Particle Swarm Optimization Based Method for Optimal Location of Photovoltaic Grid-connected Systems," Electr. Power Components Syst., vol. 38, no. 10, pp. 1123-1138, Jul. 2010.

[15] A. Ali, N. Mohd Nor, T. Ibrahim, and M. Fakhizan Romlie, "Sizing and placement of battery-coupled distributed photovoltaic generations," J. Renew. Sustain. Energy, vol. 9, no. 5, p. 053501, Sep. 2017.

[16] S. B. Jeyaprabha and A. I. Selvakumar, "Optimal sizing of photovoltaic/battery/diesel based hybrid system and optimal tilting of solar array using the artificial intelligence for remote houses in India," Energy Build., vol. 96, pp. 40-52, Jun. 2015.

[17] R. R. Gonçalves, J. F. Franco, and M. J. Rider, "Short-term expansion planning of radial electrical distribution systems using mixed-integer linear programming," IET Gener. Transm. Distrib., vol. 9, no. 3, pp. 256-266, Feb. 2015.

[18] J. F. Franco, M. J. Rider, M. Lavorato, and R. Romero, "Optimal Conductor Size Selection and Reconductoring in Radial Distribution Systems Using a Mixed-Integer LP Approach," IEEE Trans. Power Syst., vol. 28, no. 1, pp. 10-20, Feb. 2013.

[19] P. M. Pardalos, "Convex optimization theory," Optim. Methods Softw., vol. 25, no. 3, pp. 487, Jun. 2010.

[20] J. Fortuny-Amat and B. McCarl, "A Representation and Economic Interpretation of a Two-Level Programming Problem," $J$. Oper. Res. Soc., vol. 32, no. 9, p. 783, Sep. 1981.

[21] IEEE Std 1547.4, "IEEE Guide for Design, Operation, and Integration of Distributed Resource Island Systems with Electric Power Systems," Institute of Electrical and Electronics Engineers, 2011.

[22] J. J. Grainger and W. D. Stevenson, "Análisis de Sistemas de Potencia. New York; London: McGraw-Hill.," 2001.

[23] GIMEL; UPME, "Costos Nivelados de Generación de Electricidad en Colombia." [Online]. Available: https://docplayer.es/64352257-Costosnivelados-de-generacion-de-electricidad-encolombia-grupo-gimel-y-microeconomiaaplicada.html. [Accessed: 05-Sep-2018]. 


\section{ANNEXES}

\section{A. Annex: Parameters of the isolated mini-grid}

Table 3 shows the parameters of the lines and Table 4 lists the values of the active and reactive powers of each node in the scheme of the isolated mini-grid in Fig. 5.

Table 3. Parameters of the lines. Source: CHEC, the company that operates the actual grid on which the model in this study is based.

\begin{tabular}{rrrrr}
\hline \multicolumn{2}{c}{$\begin{array}{l}\text { Set of } \\
\text { lines }\end{array}$} & \multicolumn{1}{l}{$\mathbf{R}[\mathbf{o h m}]$} & $\mathrm{X}$ [ohm] & IMAX [A] \\
\hline 1 & 2 & 0.0199578 & 0.00818071 & 240 \\
\hline 2 & 3 & 0.03579528 & 0.0146725 & 240 \\
\hline 3 & 4 & 0.02311242 & 0.00947379 & 240 \\
\hline 4 & 5 & 0.0144855 & 0.00593761 & 240 \\
\hline 5 & 6 & 0.04226547 & 0.01732463 & 240 \\
\hline 1 & 7 & 0.02765121 & 0.01133424 & 240 \\
\hline 7 & 8 & 0.0164169 & 0.00672929 & 240 \\
\hline 9 & 10 & 0.1789764 & 0.04087337 & 120 \\
\hline 1 & 11 & 0.03553776 & 0.01456694 & 240 \\
\hline 11 & 12 & 0.06644016 & 0.02723384 & 240 \\
\hline 12 & 13 & 0.04342431 & 0.01779964 & 240 \\
\hline 13 & 14 & 0.04896099 & 0.02006912 & 240 \\
\hline
\end{tabular}

Table 4. Active and reactive power of each node. Source: CHEC, the company that operates the actual grid on which the model in this study is based.

\begin{tabular}{crr}
\hline $\begin{array}{c}\text { Node } \\
\text { set }\end{array}$ & Pd [kW] & Qd [kVAr] \\
\hline 2 & 72.96 & 23.984 \\
\hline 4 & 191.52 & 62.944 \\
\hline 5 & 640 & 480 \\
\hline 6 & 285.6 & 176.992 \\
\hline 7 & 182.4 & 59.952 \\
\hline 9 & 204 & 126.432 \\
\hline 10 & 230.4 & 172.8 \\
\hline 11 & 145.92 & 47.968 \\
\hline 12 & 640 & 480 \\
\hline 13 & 204 & 126.432 \\
\hline
\end{tabular}

